\title{
Cardiac amyloidosis and surgery. What do we know about rare diseases?
}

\author{
Carlos Mestres ${ }^{1}$ and Mathias van Hemelrijck ${ }^{2}$ \\ ${ }^{1}$ University Hospital Zurich \\ ${ }^{2}$ UniversitatsSpital Zurich
}

May 3, 2021

Commentary to JOCS-2020-RA-1888

JOCS-2020-RA-1888 Cardiac amyloidosis in non-transplant cardiac surgery

Cardiac amyloidosis and surgery. What do we know about rare diseases?

Running Title: Cardiac amyloidosis and cardiac surgery

Carlos - A. Mestres MD PhD FETCS ${ }^{1,}$, Mathias Van Hemelrijck MD ${ }^{1}$

1 - Clinic of Cardiac Surgery, University Hospital Zürich, Zürich (Switzerland)

2 - Department of Cardiothoracic Surgery, The University of the Free State, Bloemfontein, (South Africa)

Word count (All): 1173

Word count (Text): 774

Key words : Cardiac amyloidosis, cardiac surgery, rare disease

Correspondence:

Carlos A. Mestres, MD, PhD, FETCS

Clinic for Cardiac Surgery

University Hospital Zürich,

Rämistrasse 100

CH 8091 Zürich (Switzerland)

Email: Carlos.Mestres@usz.ch

Rare diseases are serious, chronic and potentialy lethal. The European Union (EU) definition of a rare disease is one that affects fewer than 5 in 10,000 people (1). In the EU, these rare diseases are estimated to affect up to $8 \%$ of the roughly 500 million population (2). In the United States, a rare disease is defined as a condition affecting fewer than 200,000 people in the US (3). This a definition created by Congress in the Orphan Drug Act of 1983 (4). Therefore, the estimates for the US are that 25-30 million people are affected by a rare disease. There are more than 6000 rare diseases and $80 \%$ are genetic disorders diagnosed during childhood. Despite all community efforts, there are still a lack of an universal definition of rare diseases. This was addressed a few years back by the International Society for Pharmacoeconomic and Outcomes Research (ISPOR) (5). 
Amyloidosis is a rare disorder classified in different types. It is registered in the National Organization for Rare Disorders (NORD) database (6), where a report can be found addressing fundamentals for patients, relatives and clinicians. Although classified as rare disease, it seems that amyloidosis is increasingly being recognized as a cause of heart failure (7). The European Society of Cardiology has promptly recognized this in a recent position paper published by its Working Group on Myocardial and Pericardial Disease (8). Its potential role in heart failure with preserved ejection fraction and eventual therpeutic approach have recently been hihglighted in some reviews $(9,10)$.

Having said that, Smith et al from London present in this issue of the Journal (11) an interesting review proposal with regards cardiac amyloidosis in non-transpant cardiac surgery. As briefly stated by the authors, heart transplantation is becoming the ultimate therapeutic tool in light-chain amyloidosis (AL) and transthyretin amyloidosis (ATTR), with some interesting short-term outcomes reported in some contributions like the recent from Vaidya et al (12). These authors report an overall three-year survival of $81.6 \%$ in a series of 51 patients. However, this is not, as described in their title, the focus of the authors.

With the assumption that heart transplantation works acceptably in selected patients, an important statement in this contribution by Smith et al (11) is that it is difficult to find a strong justificaton to recommend a cardiac surgical intervention in patients with cardiac amyloidosis. There are reasons to understand that these patients, regardless of the clinical problem eventually requiring cardiac surgery, namely aortic stenosis, mitral disease or coronary artery disease amenable for surgical revascularization, have clear profile for intra- and postoperative complications in the form of low output syndrom entailing significant mortality. The pathophysiological issues surrounding cardiac amyloidosis, meaning a restrictive physiologic with diastolic dysfunction and substance myocardial deposition configurate a suboptimal pattern for an extended survival.

There are still a number of issues to discuss, like ethnicity (13), familial association, prognosis on the longterm or, even, if the pandemic has brought additional burden to these patients (14). However, it is not to be forgotten that this is a technically a rare disease and collective experience, especially in the surgical field, is still scanty. In their review, Smith et al (11) discuss a number of small-sized studies and mortality. Most of these studies do not report the actual cause of death. As authors discuss about potential confounders of all these studies not knowing the actual cause of death or, as usual, not having postmortem examinations, all goes around confounders and speculation.

The readership should not incorporate confusing information. As per some types of reports in the literature, it may seem that each and every cardiac disease is amyloid-related. It is also clear that specifically dedicated centres, like the NHS National Amyloidosis Centre in London Amyloidosis Center, Boston University School of Medicine and others, may have much more information as they can collect more cases and discuss about cardiac amyloid.

After their review with focus on diagnosis, surgical risk and areas of uncertainty that require further research, some take-home messages from Smith et al (11) are that cardiac amyloidosis, per se, has intrinsic poor prognosis, that surgical treatment of diseases that may have an amyloid component like aortic stenosis need an extremely careful and accurate infividualized assessment and that, currently, heart transplantation has to be considered in specific subgroups. For the time being, the indications for non-transplant cardiac surgery seem to be restrictive. Do not forget, as stated, that rare diseases were also called "orphan diseases", and largely ignored due to poor economic potential and were thus said to be "orphaned (14). Some more time may then be needed to understand which the role of surgery may be.

\section{References}

1. Regulation (EC) No 141/2000 of the European Parliament and of the Council of 16 December 1999 on orphan medicinal products. Official Journal of the European Communities 2000; L018(43):1-6.

2. Council recommendation of 8 June 2009 on an action in the field of rare diseases (2009/C 151/02). Official J Eur Union. 2009 Jul 3;52:7-10. Availablefrom: http://eurlex.europa.eu/legalcontent/EN/TXT/?uri=OJ:C:2009:151:TOC, accessed 30 April 2021. 
3. https://rarediseases.info.nih.gov/diseases.

4. Orphan Drug Act of 1983. US Food and Drug Administration. 4 January 1983.

5. Richter T, Nestler-Parr S, Babela R; International Society for Pharmacoeconomics and Outcomes Research Rare Disease Special Interest Group. Rare Disease Terminology and Definitions-A Systematic Global Review: Report of the ISPOR Rare Disease Special Interest Group. Value Health 2015; 18:90614. doi: 10.1016/j.jval.2015.05.008.

6. https://rarediseases.org.

7. Crea F. Emerging causes and risk factors of heart failure: amyloidosis, myocarditis, immune checkpoint inhibitors, air pollution, and visceral adipose tissue. Eur Heart J. 2021; 42:1533-1537. doi: 10.1093/eurheartj/ehab214.

8. Garcia-Pavia P, Rapezzi C, Adler et al Diagnosis and treatment of cardiac amyloidosis. A position statement of the European Society of Cardiology Working Group on Myocardial and Pericardial Diseases. Eur J Heart Fail. 2021 Apr 7. doi: 10.1002/ejhf.2140.

9. van den Berg MP, Mulder BA, Klaassen SHC, Maass AH, van Veldhuisen DJ, van der Meer P, Nienhuis HLA, Hazenberg BPC, Rienstra M. Heart failure with preserved ejection fraction, atrial fibrillation, and the role of senile amyloidosis. Eur Heart J 2019;40:1287-1293.

10. Emdin M, Aimo A, Rapezzi C et al. Treatment of cardiac transthyretin amyloidosis: an update. Eur Heart J 2019;40:3699-3706.

11. Smith A, Balmforth D, Treibel T, Lall K, Oo A, Ambekar S. Cardiac amyloidosis in non-transplant cardiac surgery. J Card Surg 2021 (In press).

12. Vaidya GN, Patel JK, Kittleson M et al. Intermediate-term outcomes of heart transplantation for cardiac amyloidosis in the current era. Clin Transplant. 2021 Apr 7:e14308. doi: 10.1111/ctr.14308.

13. Staron A, Connors LH, Zheng L, Doros G, Sanchorawala V. Race/ethnicity in systemic AL amyloidosis: perspectives on disease and outcome disparities. Blood Cancer J. 2020; 10(11):118. doi: 10.1038/s41408020-00385-0.

14. Cheung RY, Cohen J, Illingworth P. Orphan Drug Plicies: Implications fort he United States, Canada and developing countries. Health Law J 2004;12:183-200. 